\title{
Correction to: Gulf Stream evolution through the Straits of Florida: the role of eddies and upwelling near Cuba
}

\author{
Yannis Androulidakis ${ }^{1}$ (D) Vassiliki Kourafalou ${ }^{1} \cdot$ Matthieu Le Hénaff ${ }^{2,3} \cdot$ Heesook Kang $^{1} \cdot$ Nektaria Ntaganou $^{1} \cdot$ \\ Chuamnin $\mathrm{Hu}^{4}$
}

Published online: 22 July 2020

(C) Springer-Verlag GmbH Germany, part of Springer Nature 2020

Correction to: Ocean Dynamics (2020) 70:1005-1032
https://doi.org/10.1007//10236-020-01381-5

The original version of this article unfortunately contained a mistake. The following Data Attribution Statement has been omitted.

Data are publicly available through the Gulf of Mexico Research Initiative Information \& Data Cooperative (GRIIDC) at https://data.gulfresearchinitiative.org (DOI: https://doi.org/10.7266/N7NG4NPG, DOI: https://doi.org/ 10.7266/n7-e1mg-8e73, DOI: https://doi.org/10.7266/n7ctpa-q845, DOI: https://doi.org/10.7266/n7-s3t7-ab53, DOI: https://doi.org/10.7266/n7-a6wv-rj68, DOI: https://doi.org/ 10.7266/n7-3s8f-m404, DOI: https://doi.org/10.7266/n70gwc-ex81, DOI: https://doi.org/10.7266/n7-memc-es11).

The online version of the original article can be found at https://doi.org/ $10.1007 / \mathrm{s} 10236-020-01381-5$

Yannis Androulidakis

iandroulidakis@rsmas.miami.edu

1 Department of Ocean Sciences, University of Miami/Rosenstiel School of Marine and Atmospheric Science (RSMAS), Miami, FL 33149, USA

2 Cooperative Institute for Marine and Atmospheric Studies (CIMAS), University of Miami, Miami, FL 33149, USA

3 NOAA/Atlantic Oceanographic and Meteorological Laboratory (AOML), Miami, FL 33149, USA

4 College of Marine Science, University of South Florida, St. Petersburg, FL 33701, USA 